\title{
Validation, reliability and operational equivalency of the nutritional screening method "Determine The Nutritional Health Of The Elderly"
}

Manuela de Almeida Roediger ${ }^{r}$

Maria de Fátima Nunes Marucci ${ }^{2}$ Maria do Rosário Dias de Oliveira Latorre ${ }^{3}$

Norman Hearst ${ }^{4}$

Cesar Messias de Oliveira ${ }^{5}$

Yeda Aparecida de Oliveira Duarte ${ }^{6}$

\section{Abstract}

Objective: To analyze the reliability, validity and operational equivalence of the nutritional screening method "Assessing The Nutritional Condition Of The Elderly". Method: This study was conducted with a subsample of 174 elderly persons from the Health, Welfare and Aging (SABE) study. The "Assessing The Nutritional Condition Of The Elderly" method consists of ten questions which classify individuals according to nutritional risk. Anthropometric and nutritional indicators were adopted as gold standard measures for comparison with the values of the method. Reliability was verified using the McNemar and Bland Altman tests, the validity of the discriminant type was assessed by the MannWhitney test and operational equivalence was identified through data relating to the time required to apply the method and the degree of understanding of the same using the Likert scale (1 to 5). Results: Of the 174 elderly persons interviewed, 63.8\% were women and $52.3 \%$ were in the $60-74$ years age group. It was found that $43.1 \%$ and $33.3 \%$ of the subjects had moderate to high nutritional risk, respectively, with a higher prevalence of high nutritional risk among women (33.3\%) and those aged 60-74 years (43.4\%). The method analyzed showed satisfactory results for reliability and discriminant validity. The average time required to apply this method was approximately seven minutes and the overall mean grade of understanding was 4.8. Conclusion: The method studied can be used by health professionals in epidemiological and clinical studies to identify the presence of nutritional risk in elderly persons living at home.

Universidade de São Paulo - USP, Faculdade de Saúde Pública, Programa de Pós-graduação Nutrição em Saúde Pública. São Paulo, São Paulo, Brasil.

2 Universidade de São Paulo - USP, Faculdade de Saúde Pública, Departamento de Nutrição. São Paulo, São Paulo, Brasil.

3 Universidade de São Paulo - USP, Faculdade de Saúde Pública, Departamento de Epidemiologia. São Paulo, São Paulo, Brasil.

4 University of California, School of Medicine. San Francisco, California, USA.

5 University College London, United Kingdom, Department of Epidemiology and Public Health. London, England.

6 Universidade de São Paulo - USP, Escola de Enfermagem, Departamento de Enfermagem Médicocirúrgica. São Paulo, São Paulo, Brasil.

Research funding: São Paulo Research Foundation (FAPESP). Research Project no 12/24567-7.
Keywords: Elderly Nutrition. Triage.

Reproducibility of Results. Nutritional Assessment. 


\section{INTRODUCTION}

The association between nutritional risk, especially malnutrition, and outcomes of disease and complications has been identified at all ages ${ }^{1-3}$. In the elderly, this nutritional disorder represents a significant public health problem in both developed and developing countries, including Brazil, due to an increased demand for health services, longer hospital stays, hospital readmission, institutionalization and lower survival rates. Undernutrition is significant among this population group as it has a higher incidence and/or prevalence ${ }^{4,5}$.

The identification of elderly people at nutritional risk, especially those living at home, is an important research topic, as it aims to guide the population and prevent future health problems due to malnutrition at an early stage ${ }^{6,7}$. In non-Brazilian studies, nutritional screening methods are recognized as viable alternatives for the identification of nutritional risk in this group, due to their low cost and ease of application, and the fact they can be used by health professionals $^{7,8}$.

Different methods for the screening of elderly people at nutritional risk have been described in scientific literature ${ }^{9-11}$. All offer advantages, disadvantages and limitations, and some have obtained satisfactory results regarding their psychometric properties (validity and reliability), operational characteristics and acceptability ${ }^{7,8}$. According to Almeida-Roediger et al. ${ }^{12}$, the nutritional screening method "Determine The Nutritional Health Of The Elderly" has been adapted for the Brazilian cultural reality and is available for the verification of psychometric properties.

This method is based on questions that can be answered by the elderly or an accompanying person, does not require specific equipment or training for body measurements, is accessible and accepted by the health professionals and the elderly persons who evaluated the method, and represents a practical, inexpensive and achievable option at the population level ${ }^{12}$. Thus, the present study validated and assessed the reliability of the nutritional screening method "Determine The Nutritional Health Of The Elderly", for use among the Brazilian elderly population.
METHOD

A validation and reproducibility study was performed with elderly persons ( $\geq 60$ years) of both genders, who were participants in the Health, Welfare and Aging Study (SABE), a longitudinal, epidemiological and home base study which was carried out in the city of São Paulo in 2000, 2006 and 2010 aimed at identifying and monitoring the living conditions of the elderly population as age increases.

The sample size was calculated based on the formula proposed by Machin et al. ${ }^{13}$, using a significance level of $5 \%$, with $90 \%$ power and a Pearson's correlation coefficient value of 0.3 , and a sample size of 80 individuals to be interviewed was identified.

The number of elderly persons (approximately 160 individuals) was doubled, however, to stratify the results of validation and reliability by gender and age group. A simple random sub-sample of 350 participants from the SABE Study was drawn to compensate for the reduction of numbers due to changes of address, death, institutionalization and refusal. Of the total of 350 elderly people, 280 were located by telephone, and of these only 240 agreed to be visited at home to conduct the interview. Of these, only 176 were located and interviewed, and two did not provide all the necessary data for the survey, giving a total of 174 individuals studied.

Two interviewers (both female, as women are more accepted by the elderly) performed data collection. Both were nutritionists, who underwent prior training, based on a general approach to the objectives of the study and guidelines on applying and completing the consent form, field questionnaire, method of nutritional screening and body measurements.

The nutritional screening method "Determine The Nutritional Health Of The Elderly" is composed of ten questions (with a yes and no dichotomous answer), as described by Almeida-Roediger ${ }^{12}$, with specific scores are assigned for each question. The sum of these corresponds to the final score which classifies individuals according to the presence or absence of nutritional risk. The questions in this 
method evaluate different areas that may affect nutritional status, including the use of medications and/or alcoholic beverages, the presence of chronic illness, inadequate food intake, oral conditions and physical limitations.

Elderly persons who obtained a final score of 0 to 2 points were classified as "good", with the recommendation of a new evaluation in six months. Those with three to five points were classified as having "moderate nutritional risk", with the elderly person being advised to improve their eating habits and lifestyle. Those who scored six or higher were classified as having "high nutritional risk," with the individual advised to seek specialized assistance from a nutritionist or physician ${ }^{12}$.

The evaluation of the reliability and validity of the "Determine The Nutritional Health Of The Elderly" method occurred over two periods: between April and July 2014 (100 individuals interviewed) and between January and March 2015 (74 individuals interviewed). The method was performed twice with the study population to evaluate reliability, at different time periods, with intervals of around 15 to 30 days, to compare the values obtained in the first (test) and second interviews (retest).

Nutritional assessment by anthropometry and nutritional indicators was adopted as a goldstandard measure (criterion or objective) to evaluate the validity of the nutritional screening method. The anthropometric variables used were arm circumference (AC), calf circumference (CC) and triceps skinfold thickness (TSF). A $1.5 \mathrm{~m}$ inelastic tape was used to perform the anthropometric measurements of AC and CC, and the Lange pachymeter with a constant pressure of $10 \mathrm{~g} / \mathrm{mm}^{2}$ was used to obtain the TSF measurement.

The nutritional indicators used were body mass index (BMI), arm muscle area (AMA) and arm muscle circumference (AMC). Body mass (BM) and height $(\mathrm{H})$ were used to calculate $\mathrm{BMI}\left(\mathrm{BM} / \mathrm{H}^{2}\right)$. Body mass was measured by means of a WISO brand portable scale with a $180 \mathrm{~kg}$ capacity and sensitivity of $100 \mathrm{~g}$; and height was measured with a Sanny brand portable stadiometer with a maximum extension of $210 \mathrm{~cm}$. To obtain AMA and AMC, AC and TSF were used, according to equations proposed in the literature ${ }^{14,15}$.
All measurements were performed in triplicate, except for $\mathrm{BM}$ and $\mathrm{H}$, which were obtained in duplicate, and the mean values were used for the analyzes, based on techniques proposed in the literature to carry out such measurements ${ }^{16}$.

The variables AC, TSF, AMA and AMC were categorized according to percentile values, with elderly persons between the 25 th and 75 th percentile considered adequate and those with a percentile $<25$ to $>75$ considered "inadequate". For the $C C$ variable, individuals with a $C C \geq 31 \mathrm{~cm}$ were considered adequate and those with $\mathrm{CC}<31 \mathrm{~cm}$ were considered inadequate. For BMI, the elderly with BMI $\geq 24$ and $<27 \mathrm{~kg} / \mathrm{m}^{2}$ were classified as adequate those with BMI $<24$ and $>27 \mathrm{~kg} / \mathrm{m}^{2}$ were considered inadequate ${ }^{5}$.

The study population was described using absolute and relative frequencies of sociodemographic variables (gender, age groups, marital status, accompanied or unaccompanied, schooling and income in minimum wages), lifestyle (alcohol intake, physical activity) and clinical data (diabetes mellitus, hypertension, cardiovascular and respiratory diseases and cancer), with the data obtained by the field questionnaire developed for this study.

Continuous variables such as the screening method score, BMI, AMA, AMC, AC, CC, TSF, and test and retest time were described in mean values, with respective standard deviations and minimum and maximum values, according to gender.

In order to perform the reliability and validity analysis, non-parametric statistical tests were used, based on the assumption that the nutrient screening, anthropometric variables and nutritional indicators did not adhere to the normality standard assessed by the Shapiro-Wilk test.

The non-parametric McNemar test and the Bland \& Altman graphs were performed for reliability. For the method to be reliable, with similar results in the two interviews, the McNemar test $p$ value between the nutritional risk diagnosis classification proposed by the method (good vs. moderate and high nutritional risk) must not be significant $(>0.05)$; and the Bland-Altman graphs must show a random distribution of residuals from the final score of the method in the test and retest stages ${ }^{17,18}$. 
The discriminant type of method validation was employed, which used the Mann-Whitney non-parametric test to compare the means of the nutritional screening method (from the first interview), with the anthropometric variables and nutritional indicators (categorized as gender and age group (60 to 74 years and 75 years and over)). In order for the method to exactly discriminate those with or without nutritional risk, the Mann-Whitney test must be significant $(p<0.05)$.

The analysis of the operational equivalence of the method was performed based on the duration of the interview and the degree of understanding of the method using the Likert scale, which uses values between 0 I didn't understand it at all and 5 I understood perfectly, and I had no questions, as suggested by Reichenheim and Moraes ${ }^{19,20}$. It was established that responses from 0 to 3 on the Likert scale would be indicative of insufficient understanding ${ }^{21}$.

The data obtained were entered in duplicate by two interviewers, and for the calculations the statistical programs available in scientific literature were used.
The study was approved by the Ethics Research Committee of the University of Public Health (FSP), of the Universidade de São Paulo (USP), Protocol $\mathrm{n}^{\mathrm{o}} 48305 / 2012$, in 22 June 2012. Once the elderly, relatives or caregivers had agreed to participate and their questions in relation to the present study were clarified they signed a Free and Informed Consent Form.

\section{RESULTS}

Of the 174 elderly people interviewed, 63.8\% were women and $52.3 \%$ were in the 60-74 age group, with a mean age of $74.3(+9.6)$ (minimum $=60$ and maximum $=96$ years). More than $50.0 \%$ of the individuals were married, accompanied, had between 1 and 7 years of study and an income of up to two minimum wages. A total of $86.8 \%$ of the elderly said they did not drink alcohol, $64.4 \%$ did not smoke and $74.7 \%$ did not practice any type of physical activity. Among the diseases evaluated, systemic arterial hypertension was most frequently $(68.4 \%)$ reported by the elderly (Table 1$)$.

Table 1. Description of study population according to socio-demographic, lifestyle and medical variables, SABE Study. São Paulo, 2014/2015.

\begin{tabular}{|c|c|}
\hline Variables & $\mathrm{n}(\%)$ \\
\hline \multicolumn{2}{|c|}{ Sociodemographic } \\
\hline \multicolumn{2}{|l|}{ Gender } \\
\hline Men & $63(36.2)$ \\
\hline Women & $111(63.8)$ \\
\hline \multicolumn{2}{|l|}{ Age group } \\
\hline 60-74 years & $91(52.3)$ \\
\hline$\geq 75$ years & $83(47.7)$ \\
\hline \multicolumn{2}{|l|}{ Marital status } \\
\hline Married & $90(51.7)$ \\
\hline Unmarried & $22(12.7)$ \\
\hline Widowed & $62(35.6)$ \\
\hline \multicolumn{2}{|c|}{ Accompanied/unaccompanied } \\
\hline Accompanied & $156(89.7)$ \\
\hline Unaccompanied & $18(10.3)$ \\
\hline \multicolumn{2}{|l|}{ Schooling } \\
\hline Illiterate (years) & $21(12.0)$ \\
\hline $1-7$ & $116(66.7)$ \\
\hline$\geq 8$ & $37(21.3)$ \\
\hline
\end{tabular}


Continuation of Table 1

\begin{tabular}{|c|c|}
\hline Variables & $\mathrm{n}(\%)$ \\
\hline \multicolumn{2}{|c|}{ Salary (in minimum salaries) } \\
\hline Up to 2 & $116(66.7)$ \\
\hline$>2-4$ & $40(23.0)$ \\
\hline$>4$ & $18(10.3)$ \\
\hline
\end{tabular}

Alcohol intake

$151(86.8)$

No

23 (13.2)

Yes

159 (91.4)

No

$15(8.6)$

Yes

$130(74.7)$

No

$44(25.3)$

Yes

Medical

Diabetes mellitus

No

$127(73.0)$

Yes

$47(27.0)$

Arterial hypertension

No

Yes

119 (68.4)

Cardiovascular disease

No

$132(75.9)$

Yes

$42(24.1)$

Respiratory disease

No

Yes

$20(11.5)$

Cancer

No $166(95.4)$

Yes 8 (4.6)

Total 174

The nutritional screening score was greater in stage 2 than in stage 1 for both the total sample (4.5 x 4.9) and both genders (4.1 x 5.1 for males and $4.7 \times 4.8$ for women). For women, the highest anthropometric variable values were found for CC and TSF (35.4 and 20.1, respectively), and the highest nutritional variable values were for the indicators of BMI and AMA (27.9 and 38.3, respectively) (Table 2). 
Table 2. Mean values of nutritional screening score at stages 1 and 2, objective measures used and time spent applying test and retest of the questionnaire, according to gender and total, SABE Study. São Paulo, 2014/2015.

\begin{tabular}{llll}
\hline \multirow{2}{*}{ Variables } & \multicolumn{1}{l}{ Men } & Women & Total \\
\cline { 2 - 3 } & \multicolumn{1}{l}{ Mean (minimum-maximum) } & $4.5(0-14)$ \\
\hline Screening score 1 & $4.1(0-10)$ & $4.7(0-14)$ & $4.9(0-14)$ \\
Screening score 2 & $5.1(1-14)$ & $4.8(0-14)$ & $27.6(14-51)$ \\
Body mass index & $27.1(18-45)$ & $27.9(14-50)$ & $37.2(13-75)$ \\
Arm muscle area & $36.5(13-75)$ & $38.3(19-65)$ & $44.9(20-82)$ \\
Arm muscle circumference & $48.3(29-75)$ & $43.0(20-81)$ & $29.6(19-41)$ \\
Arm Circumference & $29.9(22-39)$ & $29.4(19-41)$ & $35.1(24-46)$ \\
Calf circumference & $34.9(24-46)$ & $35.4(26-46)$ & $19.1(6-40)$ \\
Triceps skinfold thickness & $17.1(6-39)$ & $20.1(6-39)$ & $6.8(2-20)$ \\
Time test 1 & $6.9(2-20)$ & $6.6(3-19)$ & $5.2(2-21)$ \\
Time retest 2 & $5.3(2-19)$ & $5.1(2-21)$ & \\
\hline
\end{tabular}

When the reliability of the method was analyzed by the McNemar test, it was found that there was no significant difference between the assessment of nutritional risk (good and moderate to high nutritional risk) of the method between test and retest ( $\mathrm{p}=$ 0.0764) (data not shown). The Bland-Altman graphs were used for total, gender and age groups, and showed random distribution of residuals (Figure 1). 

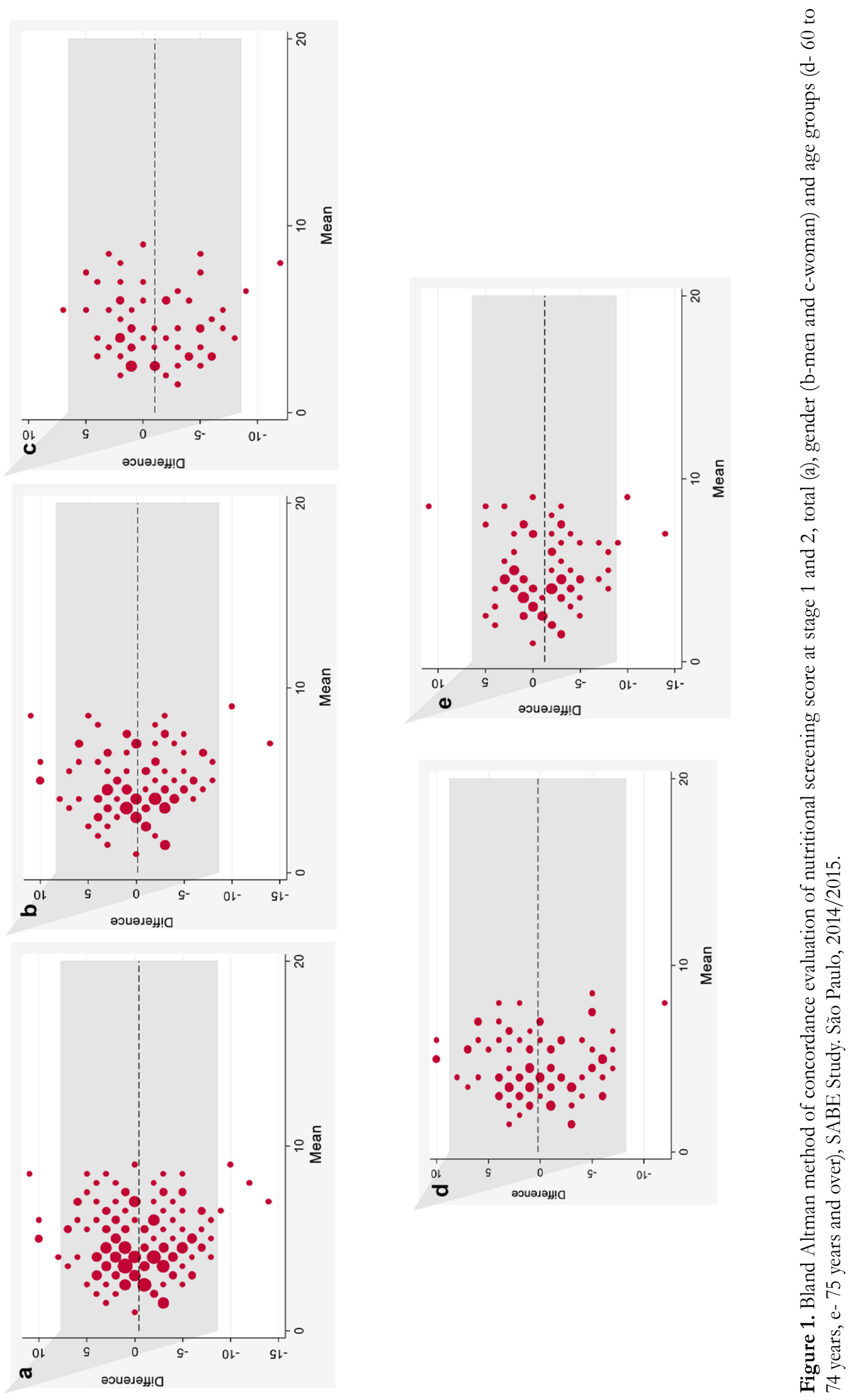
The operational equivalence of the method showed that the mean total time for performing the method was approximately seven minutes, and that application was quicker during the retest (about five minutes) and for women in both situations. The 75 years and over age group took a longer time (approximately 10 minutes) to answer the questionnaire, both in the test and in the retest, with $p<0.05$ (data not presented).

The mean overall agreement of the method by the Likert scale (between 0 and 5) was $4.8(+0.52)$ (minimum $=3$ and maximum $=5$ ), and the age group of 75 years and over had the lowest reported value [mean $4.6(+0.64)$; minimum $=3$ and maximum $=5$ ].
Question 6 Do you sometimes not have enough money to buy food? and Question 10 Are you sometimes physically unable to shop, cook or eat alone? had the lowest understanding scores (data not shown).

In the discriminant validity results, a significant difference was observed for BMI, AMC, CC and AC in the Mann-Whitney analysis in comparison with the nutritional screening score of the method. The mean scores of those classified as adequate were lower than those of individuals identified as inadequate. These differences remained significant when stratification by gender and age group was analyzed. These results show that the method studied is capable of correctly discriminating nutritional risk (Table 3).

Table 3. Discriminant validation of the method "Determine The Nutritional Health Of The Elderly" according to measures adopted by total, gender and age group, SABE Study, São Paulo, 2014/2015.

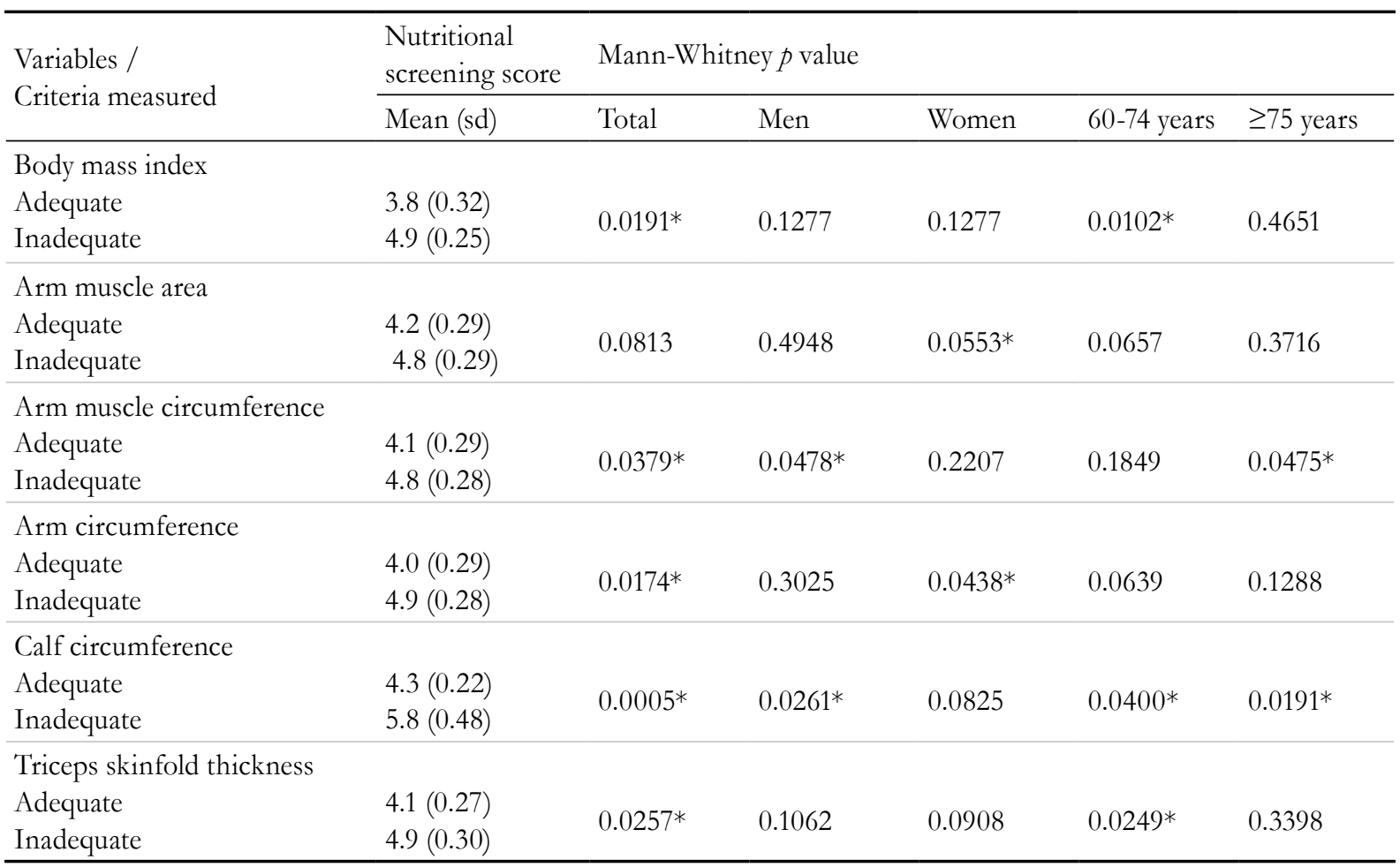

*Non-parametric Mann-Whitney test, with 5\% level of significance; sd=standard-deviation.

\section{DISCUSSION}

This is the first Brazilian study to describe the psychometric properties of the method "Determine The Nutritional Health Of The Elderly" through an analysis of reliability, discriminant validity and operational equivalence, for use by health professionals, especially nutritionists, with elderly persons residing in the home.

The results of the present study showed that the method analyzed presented higher values for reliability than the original (Determine Your Nutrition Health ${ }^{\circledR}$ - DNH) even when using another statistical test to 
confirm this psychometric property. According to Wojszel $^{22}$, the internal consistency analysis of the DNH method was used to determine its reliability through the Cronbach's Alpha coefficient, obtaining a value of 0.44 , which was considered by the author as insufficient. Based on these considerations, the quality of the process of cross-cultural adaptation of the method analyzed, performed by AlmeidaRoediger et al., can be confirmed ${ }^{12}$.

No study was found in scientific literature using the "adequate" statistical test for validation analysis of the DNH method. The localized studies ${ }^{23,24}$ used "sensitivity and specificity" analyzes as an alternative validation method, with these analyzes performed after the validation process to obtain reference values. Nevertheless, the discriminant validation results of the method analyzed in this study showed that it could correctly discriminate those with nutritional risk, attesting to the ability of the method to confirm the characteristic it proposed to measure, in this case the presence or absence of nutritional risk.

The operational equivalence of a method is an indispensable item for analyzing how easy it is to understand and thus provide results in relation to its acceptability by the population studied ${ }^{7,8,25,26}$. In the present study the method analyzed exhibited sufficient results (average of 4.8 by the Likert scale) in relation to understanding, with answers between 0 and 3 considered indicators of insufficient understanding. It can be inferred that the method was accepted by the elderly persons interviewed, as was verified in other studies using the original $\mathrm{DNH}^{7}$ method ${ }^{8,23,24}$.

Based on the results obtained, it is found that approximately $75.0 \%$ of the elderly interviewed were at nutritional risk, and that women had a higher prevalence of high nutritional risk than men. A crosssectional and multicentric study in Spain involving 1,320 elderly people over 65 years old and another in Turkey with the same age group, also identified a higher prevalence of high nutritional risk in women ( $46.2 \%$ and $36.9 \%$, respectively) than men (43.2\% and $34.3 \%$, respectively) $)^{27,28}$.

Based on the considerations presented, it can be affirmed that the nutritional screening method "Determine The Nutritional Health Of The Elderly" is not a method of clinically diagnosing malnutrition in the elderly, nor is it intended to replace comprehensive assessments of nutritional status as recommended in other nutritional screening methods ${ }^{23,29}$. Nevertheless, it can predict the general state of health and nutrition, identifying those who may or may not be at moderate to high nutritional risk $^{22,23}$. This method was originally conceived as an educational alternative designed to alert elderly persons or those responsible for them to the health problems related to the presence of nutritional risk ${ }^{29}$. In clinical practice it can be used as a preliminary method to track or identify individuals at nutritional risk and to subsequently direct them to a more complete and detailed nutritional assessment ${ }^{22-24,29}$.

Some limitations of the present study were identified. The method analyzed is based on questions that assess the most common risk conditions for the development of nutritional disorders such as malnutrition and/or obesity, and many "risk group" individuals are therefore identified. However, it is emphasized that only through an accurate evaluation of nutritional status can real cases of such disorders be identified ${ }^{8}$.

Another limitation refers to the cognitive limitations of the elderly and memory bias, which may interfere in the answering of the questions of the method studied, but which can be minimized with the presence of another responsible person such as a son or daughter or caregiver to help with clarifications where necessary. The lack of gold standard methods for assessing nutritional risk in individuals also represents a limitation, favoring the use of methods that are less "precise" for the analysis of this issue, as well as studies for the validation and reliability of the original DNH method using standardized or even "adequate" statistical tests for the analysis of such psychometric properties, thus recommending further evaluation of this method in other cultures or countries.

Despite these limitations, the original DNH method has been used in several studies worldwide $^{22-24,30,31}$ and in Brazil ${ }^{32-34}$ to evaluate the nutritional risk of the elderly. Due to its simplicity, which is a great advantage, and the fact that it does not rely on anthropometric indicators or laboratory data (difficult to evaluate in epidemiological studies and especially among elderly persons residing in the community seeking basic health care) and allows the evaluation of the impact of individual and population 
risk factors on health and nutrition, the validation of the nutritional screening method, "Determine The Nutritional Health Of The Elderly" addresses the lack of methods of this nature validated for use among the Brazilian elderly population, aimed at the early identification of nutritional disorders and subsequent nutritional intervention.

\section{CONCLUSION}

The nutritional screening method, "Determine The Nutritional Health Of The Elderly" presented satisfactory results for reliability, discriminant validity and operational equivalence, and can be used in epidemiological and clinical studies to identify the presence of nutritional risk in domiciled elderly persons. It is recommended that Brazilian health professionals, especially those working in Geriatrics and Gerontology, consider applying this method in the first appointments of individuals in various care settings, such as in the community, clinics, hospitals, outpatient clinics and long-term care facilities for the elderly (LTCFs), with the purpose of identifying, at an early age, elderly persons at nutritional risk, to subsidize nutritional intervention strategies before the problem worsens. A method such as this, which raises awareness and promotes an increase in the knowledge of individuals regarding health, food and nutrition conditions, is essential and of great potential benefit in preventing nutritional disorders and associated complications.

\section{REFERENCES}

1. Rojer AGM, Kruizenga HM, Trappenburg MC, Reijnierse EM, Sipilä S, Narici MV, et al. The prevalence of malnutrition according to the new ESPEN definition in four diverse populations. Clin Nutr. 2015:1-5. No prelo.

2. Agarwalla R, Saikia AM, Baruah R. Assessment of the nutritional status of the elderly and its correlates. J Fam Community Med. 2015;22(1):39-43.

3. Saka B, Kaya O, Ozturk GB, Erten N, Karan MA. Malnutrition in the elderly and its relationship with other geriatric syndromes. Clin Nutr. 2010;29(6):745-8.

4. Ferreira LS, Amaral TF, Marucci MFN, Nascimento LF, Lebrão ML, Duarte YA. Undernutrition as a major risk factor for death among older Brazilian adults in the community-dwelling setting: SABE survey. Nutrition. 2011;27(10):1017-22.

5. Almeida MF, Marucci MFN, Gobbo LG, Ferreira LS, Dourado DAQS, Duarte YAO, et al. Anthropometric Changes in the Brazilian Cohort of Older Adults: SABE Survey (Health, Well-Being, and Aging). J Obes. 2013;1-9.

6. Hamirudin AH, Charlton K, Walton K, Bonney A, Potter J, Milosavljevic M, et al. Feasibility of implementing routine nutritional screening for older adults in Australian general practices: a mixedmethods study. BMC Fam Pract. 2014;15:1-12.
7. Donini LM, Poggiogalle E, Molfino A, Rosano A, Lenzi A, Rossi Fanelli F, et al. Mini-Nutritional Assessment, Malnutrition Universal Screening Tool, and Nutrition Risk Screening Tool for the nutritional evaluation of older nursing home residents. J Am Med Dir Assoc. 2016;17(10):11-8.

8. Phillips MB, Foley AL, Barnard R, Isenring EA, Miller MD. Nutritional screening in communitydwelling older adults: a systematic literature review. Asia Pac J Clin Nutr. 2010;19(3):440-9.

9. Rubenstien L, Harker J, Salva A, Guigoz Y, Vellas $B$. Screening for undernutrition in geriatric practice: developing the short-form Mini Nutritional Assessment (MNA-SF). J Gerontol Ser A Biol Sci Med Sci. 2001;56(6):366-72.

10. Söderhamn U, Dale B, Sundsli K, Tomstad ST, Söderhamn O. Psychometric testing of the Norwegian version of the nutritional form for the elderly among older home-dwelling people. J Multidiscip Healthc. 2012;5:121-8.

11. Keller H, Goy R, Kane S. Validity and reliability of SCREEN II (seniors in the community: risk evaluation for eating and nutrition, Version II). Eur J Clin Nutr. 2005;59(10):1149-57.

12. Almeida-Roediger, Marucci MFN, Latorre MRDO, Hearst N, Oliveira C, Duarte YAO, et al. Adaptação transcultural para o idioma português do método de triagem nutricional Determine Your Nutritional Health ${ }^{\circledR}$ para idosos domiciliados. Ciênc Saúde Coletiva. 2017;22(2):509-18. 
13. Machin D, Campbell M, Fayers P, Pinol A. Sample size table for clinical studies. $2^{\text {a }}$ ed. Oxford: Blackwell Scientific Publications; 1997.

14. Gurney JM, Jelliffe DB. Arm anthropometry in nutritional assessment: nomogram for rapid calculation of muscle circumference and cross-sectional muscle and fat areas. Am J Clin Nutr. 1973;26(9):912-5.

15. Heymsfield SB, Mcmanus C, Smith J, Tevens V, Nixon DW. Anthropometric measurement of muscle: revised equations for calculation bone-free arm muscle area. Am J Clin Nutr. 1982;36(4):680-90.

16. Lohman TG, Roche AF, Martorell R. Anthropometric standardization reference manual. Champaign: Human Kinetics Books; 1988.

17. Bartko JJ, Carpenter Jr WT. On the methods and theory of reliability. J Nerv Ment Dis. 1976;163(5):307-17.

18. Bland JM, Altman DG. Measuring agreement in method comparison studies. Stat Methods Med Res.1999;8(2):135-60.

19. Reichenheim ME, Moraes CL. Operacionalização de adaptação transcultural de instrumentos de aferição usados em epidemiologia. Rev Saúde Pública. 2007;41(4):5-73.

20. Reichenheim ME, Hökerberg YHM, Moraes CL. Assessing construct structural validity of epidemiological measurement tools: a seven-step roadmap. Cad Saúde Pública. 2014;30(5):927-39.

21. Conti MA, Ferreira MEC, Amaral ACS, Hearst N, Cordás TA, Scagliusi FB. Equivalência semântica da versão em português do "Body Change Inventory". Ciênc Saúde Coletiva. 2012;17(9):2457-69.

22. Wojszel ZB. Use of NSI Determine Checklist to assess the risk of malnutrition in persons of advanced old age living in rural areas. Prog Health Sciences. 2012;2(1):68-75.

23. Posner B, Jette A, Smith K, Miller D. Nutrition and health risks in the elderly: the nutrition screening initiative. Am J Public Health. 1993;83(7):972-8.

24. Patterson AJ, Young AF, Powers Jr, Brown WJ, Byles JE. Relationships between nutrition screening checklists and the health and well-being of older australian women. Public Health Nutr. 2002;5(1):65-71.
25. Green SM, Watson R. Nutritional screening and assessment tools for older adults: literature review. J Adv Nurs. 2006;54(4):477-90.

26. Green SM, Watson R. Nutritional screening and assessment tools for use by nurses: literature review. J Adv Nurs. 2005;50(1):69-83.

27. Poulia KA, Yannakoulia M, Karageorgou D, Gamaletsou M, Panagiotakos DB, Sipsas NV, et al. Evaluation of the efficacy of six nutritional screening tools to predict malnutrition in the elderly. Clin Nutr. 2012;31(3):378-85.

28. Winter J, Flanagan D, McNaughton SA, Nowson C. Nutrition screening of older people in a community general practice, using the MNA-SF. J Nutr Health Aging. 2013;17(4):322-5.

29. Tavares EL, Santos DM, Ferreira AA, Menezes MFG. Avaliação nutricional de idosos: desafios da atualidade. Rev Bras Geriatr Gerontol. 2015;18(3):643-50.

30. Sinnett S, Bengle R, Brown A, Glass AP, Johnson MA, Lee JS. The validity of Nutrition Screening Initiative DETERMINE Checklist responses in older Georgians. J Nutr Elder. 2010;29(4):393-409.

31. Sugiura Y, Tanimoto Y, Imbe A, Inaba Y, Sakai S, Shishikura K, et al. Association between functional capacity decline and nutritional status based on the nutrition screening initiative checklist: a 2 -year cohort study of japanese community-dwelling elderly. PLoS One. 2016;11(11):1-6.

32. Alvarenga MRM, Oliveira MAC, Faccenda O, Amendola F. Avaliação do risco nutricional em idosos atendidos por Equipes de Saúde da Família. Rev Esc Enferm. 2010;44(4):1046-51.

33. Santos AH, Dallepiane LB, Kirchner RM, Silva FP, Bolner BB, Hert A. Triagem nutricional: identificação de alterações nutricionais na atenção à saúde do idoso. Rev Bras Ciênc Envelhec Hum. 2013;10(2):170-80.

34. Viera LS. Avaliação do risco nutricional em idosos residentes na zona urbana do município de Pelotas, RS [Dissertação]. Pelotas: Universidade Federal de Pelotas; 2015. 